\title{
Location Matters: Distinct Cognitive and Academic Profiles of Students from Rural versus Urban Poverty
}

\author{
Michele Tine \\ Department of Education, Dartmouth College, Hanover NH, United States \\ Email: michele.tine@dartmouth.edu
}

\begin{abstract}
It is essential to understand the strengths and weaknesses of students from distinct contexts so efficacious support can be designed. But, thus far research samples have been drawn almost exclusively from urban areas. Inadvertently, urban findings have been generalized to rural populations. This study addresses this issue by (a) comparing the unique cognitive processing abilities of students who grew up in low-income rural, low-income urban, high-income rural, and high-income urban contexts and (b) determining the relationship between their cognitive processing and academic achievement. Participants completed cognitive processing tasks measuring incidental memory, language, and inhibition as well as an academic achievement task. Low-income rural students exhibited distinct patterns from low-income urban students. The low-income rural students had lower inhibition scores and, unlike the other three groups, inhibition did not account for a signification portion of variance in their academic achievement scores. Potential explanations and implications of these rural-urban differences are discussed.
\end{abstract}

Keywords: Poverty, cognition, academic achievement, rural.

\section{Introduction}

A pervasive income-achievement gap persists despite substantial efforts from policy makers, educators, parents, and students (Bradley \& Corwyn, 2002; McLoyd, 1998; Reardon, 2011). Students from higherincome communities outperform students from lower-income communities from pre-K through college and across a variety of academic domains, including reading, math, and science (National Center for Education Statistics, 2017). Work also has explored domain general cognitive processes (e.g., working memory, language, incidental memory, and inhibition) that underlie the income differences across various academic domains (Fernald, Weber, Galasso \& Ratsifandrihamanana, 2011; Farah et al., 2006; Kishiyama, Boyce, Jimenez, Perry \& Knight, 2009; Noble, McCandliss \& Farah, 2007; Noble, Norman \& Farah, 2005).

Efforts to determine why students from lower-income communities perform relatively poor on these cognitive processing measures highlight the role of chronic stress. For some time it has been established that individuals living in poverty experience greater chronic stress than those living in higher-income contexts (e.g., Almedia, Neupert, Banks \& Serido, 2005; Evans \& English, 2002). It has been more recently established that the experience of chronic stress mediates the relationship between income and (at least one measure of) cognitive processing (Evans \& Schamberg, 2009). Specifically, the longer people live in poverty, the higher the amount of chronic stress they experience, and, in turn, the greater the reduction in the functioning of their working memory (Evans \& Schamberg, 2009). This implies that the chronic stress of living in poverty negatively impacts working memory (Evans \& Schamberg, 2009).

It is important to keep in mind, however, that there are different types of poverty and that different types of poverty are associated with different types of chronic stress. For example, the chronic stress experienced by those living in urban poverty includes overcrowding, noise and air pollution, high crime rates, and exposure to violence (Bobo, 2009; Evans, 2006; Power, 1996). In contrast, the chronic stress experienced in rural poverty includes isolation, lack of infrastructure, and inaccessibility to reliable transportation (Bobo, 2009; Power, 1996; Duncan, Brooks-Gunn, Yeung \& Smith, 1998; Amato, 1993). If chronic stress is related to working memory (e.g., Evans \& Schamberg, 2009) and the chronic stress experienced in urban poverty is different from that in rural poverty (e.g., Bobo, 2009), it follows that the working memory abilities of those living in urban and rural poverty might differ. An earlier study of 
ours set out to determine if this was the case (Tine, 2014). Indeed, children growing up in rural poverty exhibited worse visuospatial working memory but better verbal working memory than those living in urban poverty (Tine, 2014). These results suggest that different types of poverty are associated with different cognitive abilities (Tine, 2014).

The primary goal of the current study was to extend the aforementioned working memory findings and document a more complete cognitive profile of individuals growing up in low-income rural versus urban contexts and, for comparison reasons, high-income rural versus urban contexts. Specifically, the current study set out to determine if individuals from these different contexts vary on the other cognitive processes already known to be associated with poverty: language, incidental memory, and inhibition (Fernald, Weber, Galasso \& Ratsifandrihamanana, 2011; Farah et al., 2006; Kishiyama, Boyce, Jimenez, Perry \& Knight, 2009; Noble, McCandliss \& Farah, 2007; Noble, Norman \& Farah, 2005).

These cognitive processes - language, incidental memory, and inhibition - have important practical implications. For example, there is evidence to support their association with academic achievement; language is highly related to reading ability (e.g., Campbell et al., 2001; Izard et al., 2001; Kastner et al., 2000), incidental memory is related to language learning (Spade \& Tomita, 2010), and inhibition is related to math achievement in young students (Blair \& Razza, 2007; Bull, Espy \& Wiebe, 2008; Clark, Pritchard \& Woodward, 2010) and math, reading, and science achievement in older students (Diamond, 2013; St. Clair-Thomspon \& Gathercole, 2006). Furthermore, when taken together, these cognitive processes partially explain the income-achievement gap that exists between groups of urban students from higher- and lower-income levels (Nesbitt, Baker-Ward \& Willoughby, 2013). That is, the income level of urban students has an indirect effect on achievement through its effect on cognitive processing. However, the relationship among income level, achievement, and cognitive processing has not been documented with rural students. Therefore, the secondary goal of this study was to document the relationship between cognitive processing (i.e., language, incidental memory, inhibition) and academic achievement among students situated in low-income rural or urban contexts and, for comparison purposes, high-income rural or urban contexts.

This work is critical. Researchers have begun to recommend that the field of education, as a whole, focus on improving students' cognitive processes as a way to boost academic performance (Dunlosky, Rawson, Marsh, Nathan \& Willingham, 2013; Nesbitt, Baker-Ward, and Willoughby, 2013; While there is an abundance of research documenting the income-processing gap and income-achievement gap in urban populations from which to draw, there is a paucity of research on rural populations. Researchers and consumers of research are left unintentionally (and perhaps inaccurately) generalizing urban findings to rural populations. Meanwhile, trends show the number of individuals living in rural poverty is increasing at a faster rate than the number of individuals living in urban poverty (Fisher, 2007; Murphy, 2007). Obtaining a more thorough understanding of the cognitive and academic strengths and weaknesses of students from rural versus urban poverty will place the field of education in a better position to design appropriate and efficacious interventions based on local needs.

\section{Methods}

\subsection{Participants}

Participants included 131 (69 female, 62 male) students enrolled in a liberal arts college in the northeast U.S. Their age ranged from 17 years, 2 months to 21 years, 7 months. Participants were categorized as growing up in one of the four contexts: low-income urban, low-income rural, high-income urban, and high-income rural. The categorizations were based on their responses to the (a) low- vs. high-income and (b) rural vs. urban measures described in the Measures section. Thirty-one participants were categorized as low-income urban, 30 as low-income rural, 40 as high-income urban, and 30 as high-income rural. Seventeen additional participants were excluded from analyses because they did not indicate their family income level $(n=1)$, did not spend at least 10 years of their childhood in a household of one consistent income level $(n=4)$, indicated that their family income level fell above the low-income threshold but below the high-income threshold $(n=5)$, or were categorized as suburban $(n=7)$. Non-native English speakers were excluded from participating in the study because all tasks were presented in English. 


\subsection{Procedure}

Participants were recruited from posters and came into a laboratory on campus for approximately two hours and were tested individually on cognitive processing and academic tasks. Specifically, participants completed a(n) language, incidental memory, inhibition, and academic achievement task. These tasks were presented in a random order, with the exception that one section of the timed academic task was always presented during the mandatory 20-minute delay embedded within the incidental memory task. After completing the aforementioned tasks, participants completed a Participant Information Survey, which included items about their sex, age, race, ethnicity, language fluency, the geographic category of their hometown, and the estimated current and past household income of the home they grew up in. The Participant Information Survey was administered after the cognitive processing and academic tasks in an effort to avoid any potential demographic stereotype threat effects.

\subsection{Measures}

\section{Language Task}

Language was assessed with the Peabody Picture Vocabulary Test, 4th Edition, (PPVT-4) (Dunn \& Dunn, 2007). The researchers presented each participant with a series of pages, each with four numbered pictures and stated a word describing one of the pictures. The participant was asked to point to or say the number of the picture that the word describes. Each page was coded as correct or incorrect. Participants began the PPVT-4 at the age appropriate level, but a basal level was established when a participant correctly identified eight consecutive items and a ceiling level was established when a participant incorrectly identified six of eight consecutive items, as suggested by the PPVT-4 Manual (Dunn \& Dunn, 2007). Each participant's overall score was determined by adding the number of correct responses between the basal and ceiling levels to the initial basal score.

\section{Incidental Memory Task}

Incidental memory was assessed with two Delayed Memory for Stories Task from the Test of Memory and Learning, 2nd Edition (TOMAL 2) (Reynolds \& Voress, 2007). The researchers read two 9-sentence stories entitled "Blizzard" and "The Algebra Story" aloud to each participant. Immediately following each story, the participant had to tell the story back to the researcher. The participant received one point for each element of the story that was correctly repeated, following the TOMAL-2 instruction manual and answer key. Each participant's immediate recall score was determined by summing the points across the two stories. No participant obtained less than $80 \%$ of the possible immediate recall points. After a 20-minute delay (during which the participants all completed a 15-minute timed academic task section), the participant was asked to tell the researcher everything they remembered about the story entitled "Blizzard" story and then "The Algebra Story." Again, the participant received one point for each element of each story that they correctly repeated. The points from the delayed recalls were summed and coded as the participant's incidental memory score.

\section{Inhibition Task}

Inhibition was assessed with the Whack-A-Mole (WAM) task, a computerized version of Casey and colleagues (1997) Go/NoGo paradigm developed by the Sackler Institute (Sackler Institute, 2013). It was designed to examine how parametrically manipulating preceding context (number of Go trials) affects inhibition of a proponent response (NoGo trials) (Durston et al., 2003). On a computer screen, participants saw a picture of a mole (target stimulus) or an eggplant (non-target stimulus) pop out of a hole in a garden. Their job was to whack the mole (by pressing the spacebar) each time the mole appears on the screen, but to not whack the vegetable (by not pressing the spacebar) when it appears on the screen. The task consisted of four runs, each lasting on average 2 minutes and 21 seconds and contained an average of 53 trials, with an average of 42 Go trials and an average of 12 NoGo trials per run. The order of the NoGo trials was preprogrammed to be pseudo randomized. Stimulus duration was 1500 milliseconds and the interstimulus interval was 5 seconds. The total number of NoGo trials was automatically tracked by the program and then computed into a z-score.

\section{Academic Achievement Task}

Academic achievement was assessed with a timed paper and pencil test. There were two sections. In the math section, participants had 15 minutes to answer 10 multiple-choice items written by Educational Testing Service as practice quantitative reasoning GRE questions (Educational Testing 
Service, 2010b). In the reading section, they had 15 minutes to answer 10 multiple-choice items written by Educational Testing Service as practice verbal reasoning GRE questions (Educational Testing Service, 2010a). The academic achievement score was the proportion of total items correctly answered. Blank answers were coded as incorrect. The order of the two sections was randomized.

\section{Participant Information Survey}

Participants reported their sex, race, ethnicity, fluent languages, the geographic category of their hometown and the estimated current and past household income of the home in which they grew up. Detailed information about the geographic category and household income items is provided below.

High-income vs. low-income. Participants selected the estimated current annual household income of the home in which they grew up from the table listing annual household income levels that corresponded to different percentages of the federal poverty level used by the U.S. Department of Agriculture as eligibility guidelines for a variety of social services (U.S. Department of Agriculture, 2014). They also indicated the number of years the home in which they grew up fell at or below the current annual income they indicated. Participants were classified as low-income if they estimated the annual household income of the home in which they grew up currently fell at or below $175 \%$ of the federal poverty line and had fallen at or below that level for more than 10 years of their life. Participants were classified as high-income the annual household income of the home in which they grew up fell at or above $200 \%$ of the federal poverty line and had fallen at or above that level for more than 10 years of their life.

Rural vs. urban. Participants were categorized as rural or urban using the classification criteria set forth by the U.S. Census Bureau (U.S. Census Bureau, 2017). Participants would identify if their hometown was included on either of two provided lists, both obtained from the from the U.S. Census Bureau website (U.S. Census Bureau, 2017). If a participant identified their hometown and zip code on List A, they were classified as urban, as the cities/towns on List A were 'urban areas' according to the U.S. Census Bureau in that they had 50,000 or more individuals. If the participant identified their hometown and zip code on List B, they were categorized as suburban, as the cities/towns on List B had least 2,500 but less than 50,000 people. Note: Participants categorized as suburban were not included in analyses. If a participant identified that their home hometown and zip code were not on List A or B, they were categorized as rural, as it meant their hometown has less than 2,500 people and is therefore considered 'rural' by U.S. Census Bureau criteria.

\section{Results}

\subsection{Participant Characteristics}

Chi-square tests of independence showed no differences in gender or age distribution across the four context groups. Chi-square tests of independence also showed no differences in the income level brackets of the low-income rural vs. low-income urban groups or the high-income rural vs. the high-income urban groups. There were, however, differences in the distribution of ethnicities across the groups, $X^{2}(3$, $n=131)=23.923, p<.01$. The majority of the students identified as Caucasian in the high-income rural group (90\%) and low-income rural group (87\%). However, the majority of the students identified as an ethnic minority (i.e., American Indian, Alaska Native, Asian, Black/African American, or Pacific Islander) in the high-income urban (73\%) and low-income urban group (84\%).

\subsection{Cognitive Differences by Context}

To address the primary goal of the study and determine if there were differences in cognitive processing between participants who grew up in the four contexts, a MANOVA was run with context as the between subject variables and language, incidental memory, and inhibition scores as outcome variables. The effects for all of the analyses met the equality of error variances set by the Levene's test and equality of covariance matrices set by the Box's $M$ test. The four context groups had statistically significantly different means on the incidental memory task $\left(F(3,127)=3.317, p=.022, \eta_{p}^{2}=.074\right)$, the language task $\left(F(3,127)=3.417, p=.020, \eta_{p}{ }^{2}=.076\right)$ and the inhibition task $(F(3,127)=8.474, p$ $<.001 ., \eta_{p}{ }^{2}=.169$. See Figures 1,2 , and 3 respectively for group means. 
On the incidental memory task, Bonferroni corrected post hoc tests revealed that the high-income urban group mean was not significantly different from the high-income rural group mean $(p=.281)$. The low-income rural and urban groups were not different from one another either $(p=.955)$. There were income-related differences in the rural and urban groups, however. The low-income rural group mean score was significantly lower than the high-income rural group mean $(p=.043)$ and the low-income urban group score was significantly lower than the high-income urban group mean $(\mathrm{p}=.032)$. See Figure 1.



Figure 1. Mean incidental memory score by context

In a similar pattern, the high-income rural and urban groups did not vary from one another on the language task $(p=.249)$, neither did the low-income rural and urban groups $(p=.655)$. There were income related differences on the language task between the two urban groups: the low-income urban group scored lower than the high-income urban group $(p=.006)$. There were also differences between the two rural groups: the low-income rural group scored lower than the high-income rural group on the language task $(p=.026)$. See Figure 2.

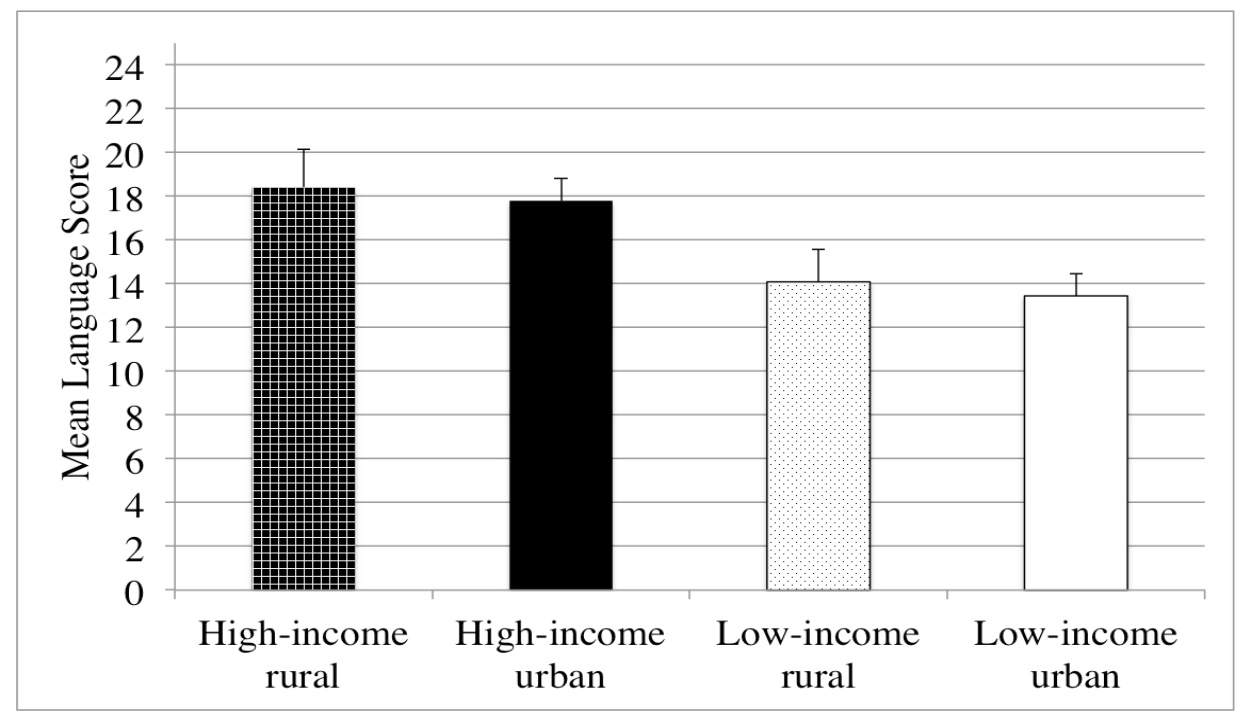

Figure 2. Mean language score by context

The inhibition task revealed the greatest number of between group differences. There were no differences between the high-income rural and high-income urban groups on the inhibition task $(p=.114)$. 
Yet, there were a number of income related differences. Specifically, the low-income urban group had a lower mean z-score than the high-income urban group on the inhibition task $(p=.032)$. Similarly, the low-income rural group had a lower mean z-score than the high-income rural group $(p=.001)$. There were also differences between the two low-income groups on the inhibition task; the mean z-score of the low-income rural group was significantly lower than that of the low-income urban group $(p=.009)$. Finally, the low-income rural group had a lower mean z-score than the high-income urban group $(p<.001)$, but the low-income urban group did not have a lower score than the high-income rural group $(p=.572)$. See Figure 3 .

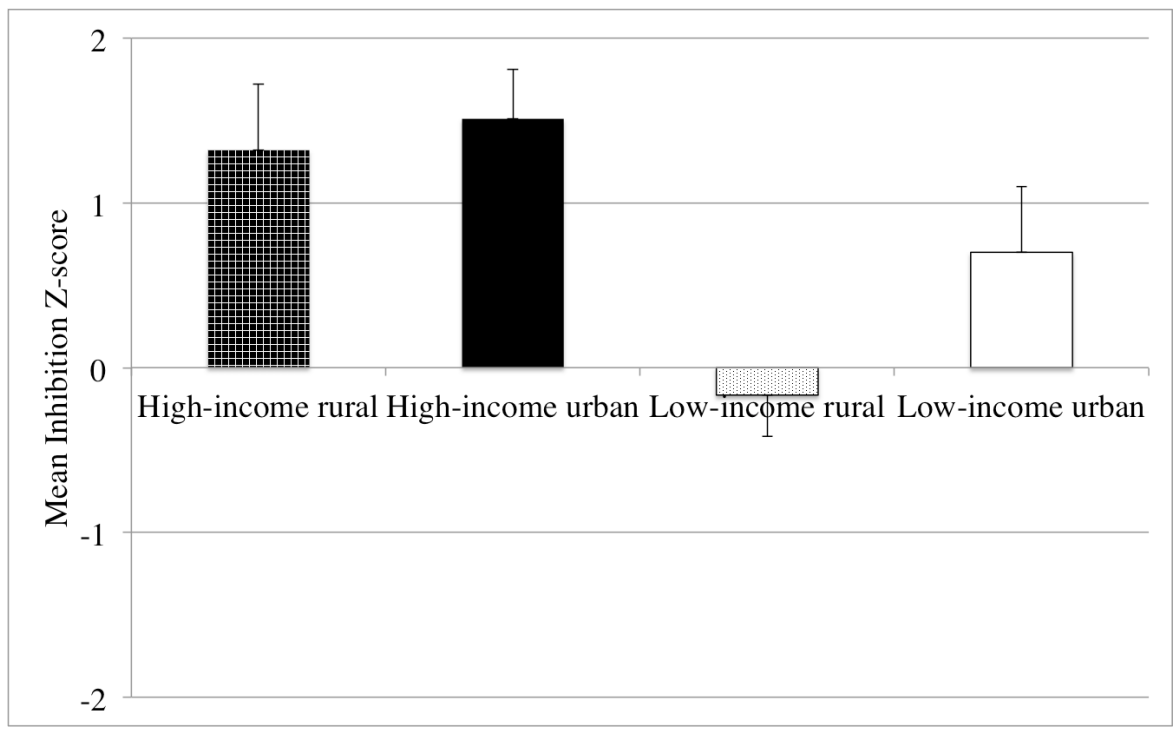

Figure 3. Mean inhibition Z-score by context

Related to the secondary goal of the study of determining if there were differences in the academic achievement as a function of context, a MANOVA was run with context as a between subjects variable and academic achievement score as the outcome variable. The analysis revealed statistical differences between the groups on the academic task, $\left(F(3,127)=7.290, p<.001, \eta_{p}{ }^{2}=.149\right)$. See Figure 4 . Bonferroni corrected post hoc tests revealed that there were no differences in academic achievement between the two high-income groups $(p=.998)$ or between the two low-income groups $(p=.976)$. However, there were income related differences. The low-income urban group scored significantly lower on the academic task than the high-income urban group $(p=.018)$ and the low-income rural group scored significantly lower than the high-income rural group $(p=.020)$.

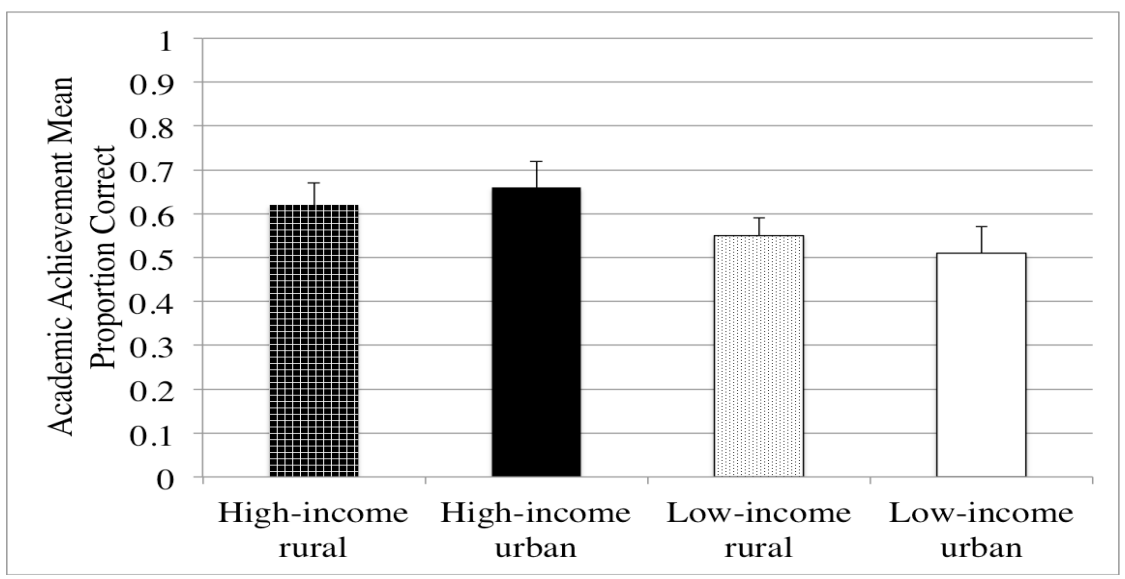

Figure 4. Academic achievement mean proportion correct by context 
To explore the relationship between cognitive processing and academic achievement, a zero-order correlation matrix was created for the cognitive and academic measures for each home environment group. See Table 1. Then, a series of multiple linear regression analyses were used to develop models to predict academic achievement from cognitive processing (i.e., predictor variables: language, incidental memory, and inhibition scores) for each context.

Table 1. Correlation matrix.

\begin{tabular}{lcccc}
\hline & Academic Achievement & Incidental Memory & Language & Inhibition \\
\hline Academic Achievement & 1.000 & .541 & .530 & .805 \\
Incidental Memory & & 1.000 & .264 & .257 \\
Language & & & 1.000 & .336 \\
Inhibition & & & & 1.000 \\
\hline
\end{tabular}

For all four contexts, cognitive processing accounted for a significant amount of variance in academic achievement. See Table 2 for statistics. However, the predictor variables that statistically accounted for the variance in academic achievement were different for the low-income rural group than for the other groups. For the (a) high-income rural, (b) high-income urban, and (c) low-income urban groups inhibition, language, and incidental memory each accounted for a significant portion of the variance in academic achievement, with inhibition accounting for the most variance in all three groups. See Table 2 for statistics. Dissimilarly, for the low-income rural group, inhibition did not account for a significant amount of the variance in academic achievement. Only language and incidental memory accounted for variance in academic achievement in the low-income rural group. See Table 2 for statistics.

Table 2. Regression statistics: cognitive processes predict academic achievement

\begin{tabular}{lccccc}
\hline Context by predictor & $\mathrm{R}^{2}$ & $\mathrm{~F}$ & $\mathrm{p}$ & $\mathrm{B}(\mathrm{SE})$ & $\mathrm{p}$ \\
\hline High-income urban & & & & & \\
Overall Model & .813 & 50.634 & .000 & & \\
Language & & & & $.046(.011)$ & .000 \\
Incidental Memory & & & & $.044(.015)$ & .006 \\
Inhibition & & & & $.593(.072)$ & .000 \\
High-income rural & & & & & \\
Overall Model & .800 & 28.041 & .000 & & \\
Language & & & & $.078(.030)$ & .016 \\
Incidental Memory & & & & $.088(.031)$ & .009 \\
Inhibition & & & & $.494(.186)$ & .015 \\
Low-income urban & & & & & \\
Overall Model & .875 & 33.869 & .000 & & \\
Language & & & & $.088(.022)$ & .000 \\
Incidental Memory & & & & $.076(.029)$ & .014 \\
Inhibition & & & & $.203(.081)$ & .017 \\
Low-income rural & & & & & \\
Overall Model & .590 & 4.633 & .010 & & \\
Language & & & & $.142(.058)$ & .021 \\
Incidental Memory & & & & $.094(.059)$ & .022 \\
Inhibition & & & $.025(.131)$ & .847 \\
\hline
\end{tabular}

\section{Discussion}

The primary goal of this study was to determine if the cognitive profiles of students from different contexts varied from one another. To address this goal, we administered a battery of cognitive processing measures to college students who had grown up in high- and low-income urban and rural contexts. Two sets of results related to the primary goal were noteworthy. First, income related differences were found on all three cognitive processing measures in the urban and rural samples. The 
high-income urban group scored significantly higher than the low-income urban group on the language, incidental memory, and inhibition tasks. These results mirror the previous work that documents an income-processing gap in urban communities (e.g., Fernald, Weber, Galasso \& Ratsifandrihamanana, 2011; Farah et al., 2006; Kishiyama, Boyce, Jimenez, Perry \& Knight, 2009; Noble, McCandliss \& Farah, 2007; Noble, Norman \& Farah, 2005). The income-processing gap was also present among the rural students; specifically, the high-income rural group scored significantly higher on the language, incidental memory, and inhibition tasks compared to their low-income rural counterparts. This first set of findings extends current literature in a critical way. Prior work shows high-income rural students perform better their low-income rural counterparts on verbal and visuospatial working memory tasks (Tine, 2014). The current results augment that finding by suggesting the income-processing gap in rural populations is not unique to working memory, but pervasive and includes a wider variety of cognitive processes including language, incidental memory, and inhibition.

Second, the current study uncovered a distinction in the cognitive processing when comparing individuals from low-income rural and urban contexts. The two groups had similar incidental memory and language scores, but their inhibition scores differed. Specifically, the inhibition scores of students who grew up in urban poverty were significantly higher than the inhibition scores of students who grew up in rural poverty. Previous work shows individuals from rural and urban poverty have distinct verbal and visuospatial working memory abilities (Tine, 2014). The current work documents a more complete cognitive profile of the two populations by determining that individuals from rural and urban poverty also have distinct inhibition abilities, but not language or incidental memory abilities. Taken together, these two general sets of findings improve our understanding of the cognitive development of individuals growing up in rural poverty- a growing, but underrepresented population (Lichter \& Schafft, 2016; Murphy, 2007; Tine, 2017).

Future work should focus on determining the reasons why those growing up in urban poverty develop stronger inhibition skills compared to those growing up in rural poverty. Extant research about aspects of the environment that impact inhibition is surprisingly limited (Matte-Gange \& Bernier, 2011), leaving only a few possibilities to consider. One possibility involves parenting, as there is a relationship between parenting and inhibition (Matte-Gange \& Bernier, 2011; Roskam, Stievenart, Meunier \& Noel, 2014). Parents who engage in (a) high levels of maternal support, monitoring, and positive parenting style, and (b) low levels of discipline and negative controlling have children with better inhibition (Roskam, Stievenart, Meunier \& Noel, 2014). Yet, there is no clear reason to believe that parents in urban poverty would be more likely to engage in these behaviors than parents in rural poverty. Prior research also shows that individuals in urban poverty have more access to social services than individuals in rural poverty, including social services related to parenting (U.S. Census, 2017). Thus, one could speculate that parents in urban poverty might engage in more ideal parenting practices than parents in rural poverty, that being parenting practices that are beneficial to inhibition. However, this line of explanation is speculative until future research is conducted. We strongly encourage such research be completed, especially considering the potential power the findings could have in supporting effective prevention/intervention services.

Alternatively, it is possible that the difference in inhibition between those from rural and urban poverty is due to a difference in computer and/or Internet use. The proportion of homes in urban poverty that have computer and Internet access is significantly higher than it is for homes in rural poverty (U.S. Department of Commerce, 2015). Computer and Intenet access is relevant to the current findings because playing action video games is positively associated with a host of abilities involved in inhibition, including response time (Castel, Pratt \& Drummond, 2005; Dye, Green \& Bavelier, 2009; Orosy-Filders \& Allan, 1989) spatial and temporal accuracy (Boot, Kramer, Simons, Fabiani \& Gratton, 2008; Donohue, Woldorff \& Mitroff, 2010; Feng, Spence \& Pratt, 2007; Green \& Bavelier, 2003, 2006, 2007), and tasks switching (Boot et al, 2008; Cain, Landau Shumamura, 2012). While not all action video games are reliant on computers and/or Internet access, the majority are (Shaw, 2010). Perhaps individuals growing up in urban poverty play more action based video games than their rural counterparts because they have sufficient computer and/or internet access and, in turn, are more familiar with the inhibitory responding that is part of many games, which could enhance their abilities on the type of task used in the current study.

There are a handful of environmental differences between rural and urban contexts, in general, that may relate to inhibition that should also be considered. For example, urban environments have more 
visual stimulation than rural environments including more traffic, crowds, buildings, and signage (U.S. Census Bureau, 2017). It seems possible that individuals in urban contexts utilize their inhibitory processes more regularly than those in rural individuals because there are more visual stimuli present to regularly inhibit. If this were the case, one might expect that both the high- and low-income urban samples would show superior inhibition compared to their high- and low-income rural counterparts. Yet, this is not what the results showed. The urban-rural inhibition difference was only present in the lowincome samples. The results make sense when we consider heritability research, however. Heritability research suggests the environment has a stronger effect on cognitive development in low-income contexts than high-income contexts (Harden, Turkheimer \& Loehlin, 2006; Turkheimer, Hlaey, Waldron, D'Onofrio \& Gottesman, 2003). The aforementioned explanations also all align with the widely accepted ideas that the brain exhibits plasticity and that the environment plays a key role in how the brain develops (Drubach, 2000). Furthermore, it fits that inhibition might be a cognitive process particularly vulnerable to environmental inputs because inhibition is specifically associated with activity in the prefrontal cortex (Hammond, Müller, Carpendale, Bibok \& Liebermann-Finestone, 2012) and the prefrontal cortex is the part of the brain most vulnerable to environmental inputs (Garon, Bryson \& Smith, 2008; Kolb, Mychasiuk, Muhammad, Li, Frost \& Gibb, 2012; Tsujimoto, 2008).

Even though the results of the current study align with work showing how the environment can influence cognitive development, it is essential to point out that the study cannot make any claims about influence or causality. The results show that rural poverty is associated with lower levels of inhibition than urban poverty, not that rural poverty causes low levels of inhibition. To make a claim about causality, participants would have needed to be randomly assigned to contexts; this process is not feasible for these contextual variables. Based on the quasi-experimental design, we cannot rule out the possibility that individuals with poor inhibition seek out or self-select into rural as opposed to urban contexts. However, this possibility seems unlikely considering how limited the opportunity for mobility is among low-income individuals (Foulkes \& Schafft, 2010), but the possibility cannot be ruled out based on the current data.

The secondary goal of the current study was to document the relationship between the cognitive processes of language, incidental memory, and inhibition with academic achievement for individuals who grew up in the four different contexts. Again, the results showed a distinct pattern for the students who grew up in rural poverty. For the other three contexts, the three cognitive processes measured in the study accounted for a significant amount of variance in academic achievement. That is, when the three cognitive processes were taken together, they accounted for more than $80 \%$ of the variance in academic achievement for those who grew up in high-income urban, high-income rural, and low-income urban contexts. This finding aligns with a large extant body of literate showing a predictive relationship between cognitive processing and academic achievement (Blair \& Razza, 2007; Bull et al., 2008; Clark, Pritchard \& Woodward, 2010; Diamond, 2013; Dunn \& Dunn, 2007; Spada \& Tomita, 2010; St. ClairThomspon \& Gathercole, 2006). Moreover, in these three contexts each individual cognitive process itself accounted for a significant amount of the variance in academic achievement. These patterns were not the same in the low-income rural sample. In the low-income rural sample, the three cognitive processes together did account for a significant portion of the variance of academic achievement, but only $59 \%$ of the variance as compared to $80 \%$ (high-income rural), $81 \%$ (high-income urban), and $86 \%$ (low-income urban) in the three other contexts. Furthermore, when the cognitive processes were examined for their individual contributions to academic achievement, it was uncovered that inhibition did not account for a significant portion of the variance in the low-income rural sample. As noted earlier, inhibition did account for a significant portion of the variance in academic achievement in the other three contexts. In fact, inhibition was the cognitive process that accounted for the most variance in the high-income urban, high-income rural, and low-income urban samples. In other words, it seems inhibition is less related to academic performance for students from rural poverty compared to individuals who grew up in other areas.

Policy makers and educators need to take findings such as these into consideration when creating research-based interventions to target specific cognitive processes as a way of improving academic outcomes. In other words, interventions and/or remediation plans should be tailored for students in rural poverty in ways that are slightly different for students from other contexts. Some interventions might want to focus on improving inhibition, but for the sake of improving inhibition itself, not necessarily for the sake of improving academic achievement. Admittedly, interventions aimed at 
improving cognitive processes have been ineffective in producing long-term and/or transferable gains thus far (see Melby-Lervag \& Hulme, 2013 for a review). Thus, educators might want to focus instead on decreasing the inhibitory demands placed on students in rural poverty (without lowering the learning objectives) and/or capitalizing on other, stronger cognitive processes that are more related to their academic achievement in this population.

It is important to keep in mind that the participants in this sample all attended a selective liberal arts institution the northeast of the United States and are likely not representative of the general population. There is no clear reason to hypothesize that the relationship between cognitive processing and academic achievement would be different among different samples, but it is certainly a possibility, and a replication study on young adults with various educational profiles is encouraged. Future work could also measure the specific stressors associated with rural and urban poverty to be able to determine the stressors that are most associated with the differences documented in the current study.

The results of the current study serve as an essential reminder as to how important it is to consider how contexts may vary and reaffirm a long-standing call for comparative quantitative research on rural versus urban contexts (see Coladarci, 2007). More importantly, the results position the field of education to design and test more appropriate and efficacious support for all students in the future.

\section{References}

1. Almeida, D.M., Neupert, S.D., Banks, S.R. \& Serido, J. (2005). Do daily stress processes account for socioeconomic health disparities? Journal of Gerontology, 60, 34-39.

2. Amato, P. R. (1993). Children's adjustment to divorce: Theories, hypotheses, and empirical support. Journal of Marriage and Family, 55, 23-38 .

3. Blair, C. \& Razza, R. P. (2007). Relating effortful control, executive function, and false belief understanding to emerging math and literacy ability in kindergarten. Child Development, 78, 647-663.

4. Bobo, L. D. (2009). Crime, urban poverty, and social science. Du Bois Review, 6, 273-278.

5. Boot, W.R., Blakely, D.P. \& Simons, D.J. (2011). Do action video games improve perception and cognition? Frontiers in Psychology, 2, 226.

6. Bradley, R.H. \& Corwyn, R.F. (2002). Socioeconomic status and child development. Annual Review of Psychology, 53, 371-399.

7. Bull R., Espy K.A. \& Wiebe S.A. (2008). Short-term memory, working memory, and executive functioning in preschoolers: Longitudinal predictors of mathematical achievement at age 7 years. Developmental Neuropsychology, 33, 205-228.

8. Cain, M.S., Landau, A.N. \& Shimamura, A.P. (2012). Action video game experience reduces the cost of switching tasks. Attention, Perception \& Psychophysical, 74(4), 641-647.

9. Campbell, F.A., Pungello, E.P., Miller,-Johnson, S., Burchinal, M. \& Ramey, C. (2001). The development of cognitive and academic abilities: growth curves from an early childhood educational experiment. Developmental Psychology, 37, 231-242.

10. Castel, A.D., Pratt, J. \& Drummond, E. (2005). The effects of action video game experience on the time course of inhibition of return and the efficiency of visual search. Acta Psychologica, 119, 217-230.

11. Casey, B. J., Trainor, R. J., Orendi, J. L., Schubert, A.B., Nystrom, L.E., Giedd, J.N., Castellanos, F.X., Haxby, J.V., Noll, D.C., Cohen, J.D., Forman, S.D., Dahl, R.E. \& Rapoport, J.L. (1997). A developmental functional MRI study of prefrontal activation during performance of a Go-No-Go task. Journal of Cognitive Neuroscience, 9, 835-847.

12. Clark, A.C., Pritchard, V.E. \& Woodward, L.J. (2010). Preschool executive function abilities predict early mathematics achievement. Developmental Psychology, 46(5), 1176-1191.

13. Coladarci, T. (2007). Improving the yield of rural education research: An Editor's swan song. Journal of Research in Rural Education, 22(3), 1-8.

14. Diamond, A. (2013). Executive functions. Annual Review of Psychology, 64, 135-168.

15. Donohue, E.E., Woldorff, M.G. \& Mitroff, S.R. (2010). Video game players show more precise multisensory temporal processing abilities. Attention, Perception, \& Psychophysics, 72(4), 1120-1129.

16. Drubach, D. (2000). The brain explained. Upper Saddle River. NJ: Prentice Hall. 
17. Dunlosky, J. Rawson, K.A., Marsh, E.J., Nathan, M.J. \& Willingham, D.T. (2013). Improving students' learning with effective learning techniques: Promising directions from cognitive and educational psychology. Psychological Science in the Public Interest, 14(1), 4-58.

18. Duncan, G. J., Brooks-Gunn, J., Yeung, W. J. \& Smith, J. R. (1998). How much does childhood poverty affect the life chances of children? American Sociological Review, 63, 406-423.

19. Dunn L.M. \& Dunn L.M. (2007). Peabody Picture Vocabulary Test. $4^{\text {th }}$ Edition. Minneapolis, MN: NCS Pearson, Inc.

20. Durston, S., Tottenham, N.T., Thomas, K.M., Davidson, M.C., Eigsti, I.M., Yang, Y., Ulug, A.M. \& Casey, B.J. (2003). Differential patterns of striatal activation in young children with and without ADHD. Biological Psychiatry, 15, 871-878.

21. Dye, M.W.G., Green, C.S. \& Bavelier, D. (2009). The development of attention skills in action video game players. Neuropsychologia, 47(8), 1780-1789.

22. Educational Testing Service (2010a). Graduate record examinations, general test, practice test 1: Verbal reasoning. Accessed on March 10, 2013 at: https://www.ets.org/gre/revised_general/prepare

23. Educational Testing Service (2010b). Graduate record examinations, general test, practice test 1: Quantitative reasoning. Accessed on March 10, 2013 at: https://www.ets.org/gre/revised_general/prepare

24. Evans, G.W. (2006). Child development and the physical environment. Annual Review of Psychology, 57, 423451.

25. Evans, G.W. \& English, K. (2002). The environment of poverty: Multiple stressor exposure, psychophysiological stress, and socioemotional adjustment. Child Development, 73, 1238-1248.

26. Evans, G. \& Schamberg, M. (2009). Childhood poverty, chronic stress, and adult working memory. Proceedings of the National Academy of Sciences, 106, 6545-6549.

27. Feng, J., Spence, I. \& Pratt, J. (2007). Playing an action video game reduces gender differences in spatial cognitive. Psychological Science, 18(10), 850-855.

28. Farah, M. J., Shera, D. M., Savage, J. H., Betancourt, L., Giannetta, J. M., Brodsky, N. L., Malmud, E.K. \& Hurt, H. ( 2006 ). Childhood poverty: Specific associations with neurocognitive development. Brain Research, $1110,166-174$.

29. Fernald, L.C.H., Weber, A., Galasso, E. \& Ratisfandrihamanana, L. (2011). Socioeconomic gradients and child development in a very low income population: Evidence from Madagascar. Developmental Science, 14, 832-847.

30. Fisher, M. (2007). Why is U.S. poverty higher in nonmetropolitan than in metropolitan areas? Growth and Change, 38, 56-76.

31. Foulkes, M. \& Schafft, K. A. (2010). The impact of migration on poverty concentrations in the United States 1995-2000. Rural Sociology, 75, 90-110 .

32. Garon, N., Bryson, S.E. \& Smith, I.M. (2008). Executive function in preschoolers: a review using an integrative framework. Psychological Bulletin, 134(1), 31-60.

33. Green, C.S. \& Bavelier, D. (2003). Action video game modifies visual selective attention. Nature, 423(6939), 534-537.

34. Green, C.S. \& Bavelier, D. (2006). Effect of action video games on the spatial distribution of visuospatial attention. Journal of Experimental Psychology, Human Perception, and Performance, 32(6), 1465-1478.

35. Green, C.S. \& Bavelier, D. (2007). Action-video-game experience alters the spatial resolution of vision. Psychological Science 18(1), 88-94.

36. Hammond, S.I., Müller, U., Carpendale, J.I., Bibok, M.B. \& Liebermann-Finestone, D.P. (2012). The effects of parental scaffolding on preschoolers' executive function. Developmental Psychology, 48(1), 271-281.

37. Harden, K. P., Turkheimer, E. \& Loehlin, J. C. (2006). Genotype by environment interaction in adolescents' cognitive aptitude. Behavior Genetics, 37, 273-283.

38. Izard, C.E., Fine, S., Schultz, D., Mostow, A., Ackerman, B. \& Youngstrom, E. (2001). Emotion knowledge as a predictor of social behavior and academic competence in children at risk. Psychological Science, 12, 18-23.

39. Kishiyama, M.M., Boyce, W.T., Jimenez, A.M., Perry, L.M. \& Knight, R.T. (2009). Socioeconomic disparities affect prefrontal function in children. Journal of Cognitive Neuroscience, 21(6), 1106-1115.

40. Kolb, B., Mychasiuk, R., Muhammad, A., Li, Y., Frost, D.O. \& Gibb,R. (2012). Experience and the developing prefrontal cortex. Proceedings of the National Academic of Sciences of the United States of America, 109(2), 17186-17193.

41. Lichter, D.T. \& Schafft, K.A. (2016). People and places left behind: Rural poverty in the new century (pp.318$340)$. 
42. In D. Brady \& L. Burton (Eds.) Oxford Handbook of the Social Science of Poverty. Oxford: Oxford University Press.

43. Matte-Gange, C. \& Bernier, A. (2011). Prospective relations between maternal autonomy support and the mediating role of child language ability. Journal of Experimental Child Psychology, 110(4), 611-625.

44. McLoyd, V.C. (1998). Children in poverty: Development, public policy, and practice. In Sigel, I. \& Renninger, K.A. (Eds.), Handbook of child psychology (5 ed., Vol. 4, pp. 35-208). New York: Wiley.

45. Melby-Lervag, M. \& Hulme, C. (2013). Is working memory training effective? A meta-analytic review. Developmental Psychology, 49, 270-291.

46. Murphy, A. K. (2007). The suburban ghetto: The legacy of Herbert Gans in understanding the experience of poverty in recently impoverished American suburbs. City \& Community, 6, 21-37.

47. National Center for Education Statistics. (2017). Nations Report Card . Retrieved from http://nces.ed.gov/ nationsreportcard/

48. Nesbitt, K.T., Baker-Ward, L. \& Willoughby, M.T. (2013). Executive function mediates socio-economic and racial differences in early academic achievement, Early Childhood Research Quarterly, 28, 774-783.

49. Noble, K. G., McCandliss, B. D. \& Farah, M. J. (2007). Socioeconomic gradients predict individual differences in neurocognitive abilities. Developmental Science, $10,464-480$.

50. Noble, K. G., Norman, M.F. \& Farah, M. J. (2005). Neurocognitive correlates of socioeconomic status in kindergarten children. Developmental Science, 8, 74-87.

51. Orosy-Filders, C. \& Allan, R.W., (1989). Psychology of computer use: XII. Videogame play: Human RT to visual stimuli. Perceptual and Motor Skills, 69, 243-247.

52. Power, T. (1996). Lost landscapes and failed economies, the search for a value of place. Washington, DC: Islands.

53. Reardon, S.F. (2011). The widening academic achievement gap between the rich and the poor: New evidence and possible explanations. In R. Murnane \& G. Duncan (Eds.), Whither Opportunity? Rising Inequality and the Uncertain Life Chances of Low-Income Children. New York: Russell Sage Foundation Press.

54. Reynolds, C. \& Voress, J.K. (2007). Test of memory and learning: $2^{\text {nd }}$ Edition. Austin, TX: PRO-ED.

55. Roskam, I., Stievenart, M., Meunier, J.C. \& Noel, M.P. (2014). The development of children's inhibition: Does parenting matter? Journal of Experimental Child Psychology, 122, 166-182.

56. Sackler Institute (2013). Whack-a-mole task. Accessed on March 24, 2013 from http://www.sacklerinstitute.org/ cornell/assays_and_tools/WackAMole/

57. Shaw, A. (2010). What is Video Game Culture? Cultural Studies and Game studies, Games and Culture, 5(4), 403-424.

58. Spade, N. \& Tomita, Y. (2010). Interactions between type of instruction and type of language feature: A metaanalysis, Language Learning, 60(2), 263-308.

59. St Clair-Thompson H.L. \& Gathercole, S.E. (2006). Executive functions and achievements in school: Shifting, updating, inhibition, and working memory. Quarterly Journal of Experimental Psychology, 59, 745-759.

60. Tine, M. (2017). Growing up in rural vs. urban poverty: contextual, academic, and cognitive differences. In G.I. Staicu (Ed.), Poverty and Deprivation. New York, NY: InTech

61. Tine, M. (2014). Working memory differences between children living in rural and urban poverty. Journal of Cognition and Development, 15(4), 599-613.

62. Tsujimoto, S. (2008). The prefrontal cortex: functional neural development during early childhood. The Neuroscientist, 14(4), 345-358.

63. Turkheimer, E., Haley, A., Waldron, M., D'Onofrio, B. \& Gottesman, I. I. (2003). Socioeconomic status modifies heritability of IQ of young children. Psychological Science, 14, 623-628.

64. U.S. Census Bureau (2017). A national list of all 2010 urbanized areas and urban clusters for the U.S., Puerto Rico, and Island Areas first sorted by state FIPS code, then by UACE code. Accessed on December 5, 2017 from http://www.census.gov/geo/reference/ua/urban-rural-2010.html

65. U.S. Department of Agriculture. (2014). Income eligibility guidelines. Retrieved from http://www.fns.usda.gov/ cnd/governance/notices/iegs/iegs.htm

66. U.S. Department of Commerce. (2015). Broadband. Retrieved from http://www.ntia.doc.gov/category/ broadband 